\title{
Distinguishing social and asocial learning using diffusion dynamics
}

\author{
SIMON M. READER \\ McGill University, Montreal, Quebec, Canada \\ and Utrecht University, Utrecht, The Netherlands
}

\begin{abstract}
Theoretical models predict that the cumulative number of individuals displaying a socially learned novel behavior will follow an accelerating pattern over time, whereas asocial processes have been associated with linear or decelerating functions. This raises the possibility that the shape of the diffusion curve may reveal something about the learning processes involved. If true, this would be particularly useful for identifying social transmission in observational field studies. Published data are reviewed and are found to provide limited support for this view. The use of accelerating curves as a diagnostic is challenging because (1) alternative theoretical models make similar predictions, (2) clear supporting empirical data are lacking, and (3) practical considerations frequently make accurate construction of the diffusion curve difficult.
\end{abstract}

The determination of whether a particular behavior pattern is acquired by social learning is a thorny and controversial issue that has received considerable scrutiny. Animal studies have tended to follow one of two traditions in addressing such issues. The laboratory tradition has provided experimental rigor, but the typical setup involving a naive observer learning from a trained demonstrator provides little information on how information may spread through a population. Laboratory experiments are also open to the criticism that they lack relevance to the challenges animals face in the wild. The field tradition is often more ecologically relevant but has tended to take an observational approach and, so, provides reports of cultural transmission that are often anecdotal, with the social learning mechanism (if any) rarely being determined. A number of researchers have suggested that the pattern of spread of a behavior through a group can reveal something about the learning processes involved and that, thereby, observational data can be used to provide evidence for or against social learning. Here, I focus on the validity of this claim, concentrating on foraging behavior, although the arguments presented apply equally to other behavioral domains, such as antipredator behavior.

A diffusion curve is a representation of the temporal spread of a behavior pattern through a group, formed by plotting the cumulative number of individuals demonstrating that behavior pattern against time. The term diffusion may be suggestive of social learning, but a novel behavior pattern (innovation) can also increase in fre-

I thank the BBSRC, the Royal Society, and the Bellairs Foundation for funding, J. R. Kendal, K. N. Laland, G. de Jong, J. J. Bolhuis, D. Sol, and L. Lefebvre for helpful discussions, and J. R. Kendal, B. G. Galef, Jr., and an anonymous referee for valuable comments on the manuscript. Correspondence concerning this article should be addressed to S. M. Reader, Behavioral Biology, Utrecht University, Padualaan 14, P.O. Box 80086, 3508 TB Utrecht, The Netherlands (e-mail: s.m.reader@bio.uu.nl). quency over time as a consequence of other processes, such as asocial (individual) learning. Theoretical analyses have raised the possibility that the shape of the diffusion curve may reveal something about the processes of learning and social interaction involved, although this exercise may be more complicated than it appears (Laland \& Kendal, 2003; Lefebvre, 1995a). Below, I will discuss these theoretical models of the diffusion process, consider the empirical support for competing models, and outline a number of practical considerations for constructing or interpreting diffusion curves. I will conclude with an outline of possible additions and alternatives to the use of diffusion curves to predict learning processes.

\section{Theory and Models}

Accelerating curves as a proposed diagnostic of social learning. Social learning refers to learning that is influenced by observation of or interaction with another animal or its products (Heyes, 1994). In general, social learning processes are argued to result in accelerating diffusion curves, such as the logistic, the exponential, or the hyperbolic sine (Boyd \& Richerson, 1985; CavalliSforza \& Feldman, 1981; Laland, Richerson, \& Boyd, 1996; Lefebvre, 1995a). Cumulative distributions characterized by nonaccelerating functions (e.g., linear or logarithmic) are thought to be compatible with asocial (individual) learning models (Lefebvre, 1995a; Roper, 1986). On this basis, the argument has been made that the shape of the diffusion curve may allow asocial and social learning to be distinguished. Figure 1 illustrates various functions that have been suggested to describe the diffusion of a novel behavior pattern through a population; the cumulative curves are shown alongside the underlying frequency distributions.

Roper (1986) has described the sigmoid (S-shaped) function as a diagnostic of social transmission that "rules 

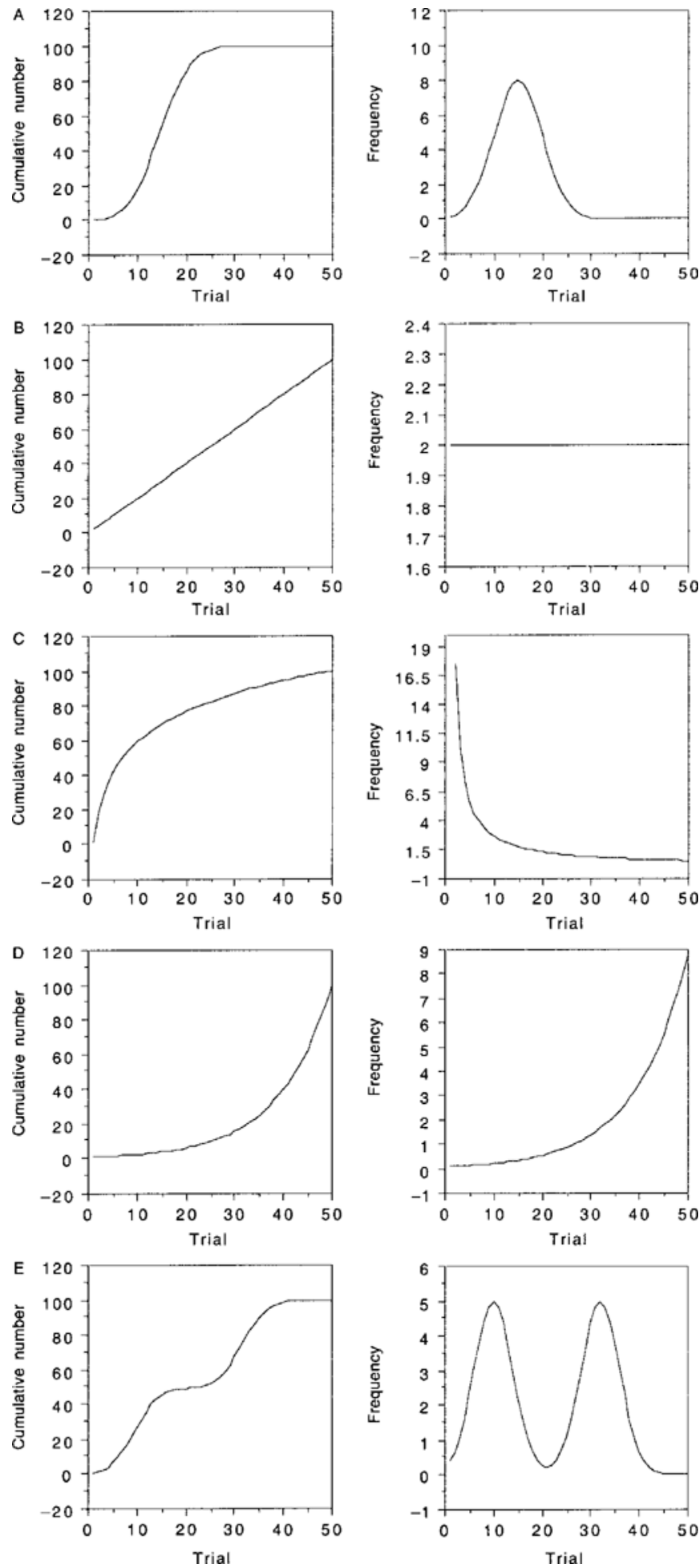

Figure 1. Illustrations of various functions that have been proposed to describe the temporal diffusion of novel behavior patterns through animal groups (Lefebvre, 1995a). Cumulative curves are shown on the left: (A) logistic $\left(y=k / 1+e^{a-r \cdot x}\right)$, (B) linear $(y=a+b \cdot x)$, (C) logarithmic $(y=a+b \cdot \log x)$, (D) exponential $\left(y=a \cdot e^{(b \cdot x)}\right)$, and (E) a step-function formed by overlaying two sigmoidal curves. The associated frequency distribution of each function is shown on the right. Note the differences in the scales on the $y$-axes. 
out" (p. 576) the possibility that animals are learning independently by trial and error. Such arguments have become prevalent in the published literature (Cloutier, Newberry, Honda, \& Alldredge, 2002; Galef, 1990; Rendell \& Whitehead, 2001; Shettleworth, 1998). For instance, Rendell and Whitehead (2001) have noted that the accelerating pattern of spread of a novel feeding technique in humpback whales (Weinrich, Schilling, \& Belt, 1992) strongly suggests social learning, given that an exponential function fits the data better than does a linear model that "would indicate individual learning" (p. 313). In humans, an exponential increase in the number of published papers on phylogenetic studies has been used to imply a pattern of cultural transmission (Pagel, 1997). However, doubt has begun to be cast on these assertions (Day, Kendal, \& Laland, 2001; Galef, 2001; Huffman \& Hirata, 2003; Laland \& Kendal, 2003; Lefebvre, 1995a; Reader, 2000; Whiten, 2000). As we shall see, the use of sigmoidal curves as a diagnostic can be criticized on several grounds: (1) Alternative models of social learning can produce a variety of shapes of diffusion curve, (2) alternative theoretical models make predictions similar to those of cultural transmission models, (3) supporting empirical data are lacking or inconsistent, and (4) practical considerations frequently raise problems for the accurate construction of the diffusion curve. The danger comes not in making predictions of the pattern of diffusion of a socially acquired behavior, but in using such predictions to diagnose underlying processes.

Social learning models. Mathematical models of cultural transmission have been developed to predict the pattern of spread of novel traits among humans (Boyd \& Richerson, 1985; Cavalli-Sforza \& Feldman, 1981), and these, together with optimal foraging models, have been applied to animal social learning (Giraldeau \& Caraco, 2000; Giraldeau, Caraco, \& Valone, 1994; Kendal, 2003; Laland et al., 1996). Most models predict that the diffusion of cultural traits will exhibit an accelerating, autocatalytic pattern over time, since the more animals there are performing the behavior, the greater the opportunity for a naive animal to see a demonstration (Boyd \& Richerson, 1985; Cavalli-Sforza \& Feldman, 1981; Laland et al., 1996; Lefebvre, 1995a, 1995b). However, models of guided variation, where individuals modify culturally acquired behavioral traits on the basis of personal experience, predict decelerating logarithmic diffusion curves (Boyd \& Richerson, 1985; Laland et al., 1996). A commonly predicted accelerating pattern is a sigmoid diffusion curve (Figure 1A; Laland et al., 1996). CavalliSforza and Feldman (1981), for example, state that if cultural innovation acquisition is followed for a sufficiently long period, the cumulative curve "almost always follows an S-shaped curve" (p. 29).

The sigmoid pattern is anticipated because, as the trait spreads, the number of demonstrators increases (enhancing the opportunity for social learning in the remaining observing individuals), but the number of individuals left to learn decreases. Early and late on in the process, the op- portunities for social learning are limited, because there are too few demonstrators and then too few observers, respectively. However, growth is rapid during the intermediate stages (Laland et al., 1996). The logistic equation is used to derive the sigmoid shape, although the equation is a descriptive tool that may not correspond to the processes underlying diffusion (Lefebvre, 1986). The sigmoid prediction has received considerable empirical support from the literature on the diffusion of innovations among humans (Rogers, 1995) and has been recognized for some time: "A slow advance in the beginning, followed by rapid and uniformly accelerated progress, followed again by progress that continues to slacken until it finally stops: These are the three ages of . . invention" (Tarde, 1903/1969, p. 127).

This kinetic explanation for the sigmoidal prediction contrasts with another model that makes the same prediction, the individualdifferences model (Cavalli-Sforza \& Feldman, 1981; Rogers, 1995). Rogers has plotted a normal distribution called the innovativeness dimension, as measured by the time it takes an individual to adopt an innovation. The fact that individuals differ in their tendency to adopt an innovation leads to an S-shaped cumulative frequency distribution (see the Asocial Learning and Individual Variation section, below). Cavalli-Sforza and Feldman (1981) have noted that individual differences in the propensity to learn of or adopt an innovation are likely to be pervasive and that a choice between the individual differences and the kinetic models cannot be made from the shapes of empirical curves alone. Furthermore, Cavalli-Sforza and Feldman (1981) have argued that the choice between these hypotheses must be made in more subtle ways, perhaps even requiring analysis of acquisition at the individual level. I will return throughout this paper to the problems involved in interpreting diffusion curves in terms of underlying process.

The kinetic logistic model makes a number of assumptions (Cavalli-Sforza \& Feldman, 1981; Laland, 1992; Lefebvre, 1986), including that (1) the probability of acquisition is proportional to the fraction of those who already have adopted and the fraction of those who have not yet adopted the innovation, (2) transmission is exclusively due to knowledge gained by observation or contact with adopters, (3) the population is spatially homogeneous, (4) acquisition of an innovation is a one-step process, (5) the "proportionality constant" (Cavalli-Sforza \& Feldman, 1981) is consistent across time and individuals, and (6) the population is large and closed. As will be described below, several of these assumptions may be violated in any particular case, resulting in different diffusion curves.

Social learning may operate through direct observation of demonstrators, but animals may also learn from cues demonstrators leave behind, such as partially exploited food sources or excretory deposits (Laland \& Plotkin, 1993; Sherry \& Galef, 1984, 1990). In some cases, such as excretory deposits, the number or strength of the cues left behind may be proportional to the number of demonstrators. In other cases, there could be a 
nonlinear relationship between the number of individuals that have acquired a behavior and the number of cues that they leave behind, violating Assumption 1 and potentially resulting in a nonsigmoid diffusion curve.

Closed populations (Assumption 6) may be rare in nature, with some level of migration being the norm. Studies of a socially acquired novel feeding behavior in pigeons demonstrated more rapid spread in free-living populations than in captive populations, probably because experienced birds can leave free-living flocks, whereas birds in captive groups can utilize food sources exposed by individuals that have already acquired the behavior (Lefebvre, 1986; Lefebvre \& Palameta, 1988). Such scrounging has been shown experimentally to reduce rates of social transmission (Giraldeau \& Lefebvre, 1987; Lefebvre, 1986) and has been shown theoretically to prevent the spread of a trait to all the members of a population (Laland et al., 1996).

Lefebvre and Giraldeau (1994) have demonstrated that, in pigeons, increasing the number of tutors increased the rate of social learning, whereas increasing the number of uninformed bystanders decreased the rate of learning. They predicted that cultural diffusion in nonhuman animals would be exponential, since, contrary to the assumptions of the logistic model, depletion of the pool of naive individuals would enhance, rather than decelerate, transmission by reducing the number of bystanders. Laland et al. (1996) confirmed that a curve resembling a positive exponential could result from frequency-dependent social learning. Several studies have demonstrated positive frequency-dependent learning, or conformist transmission, where individuals tend to do what the majority do (e.g., Beck \& Galef, 1989; Day, MacDonald, Brown, Laland, \& Reader, 2001; Laland \& Williams, 1997; Sugita, 1980). For example, female guppies preferred to follow a shoal of 10 guppies over following a shoal of 1 and learned a route preference as a result of this propensity to follow the larger group (Lachlan, Crooks, \& Laland,
1998). Alternatively, adoption of an innovation may put extra pressure on nonadopters to perform the new behavior pattern, again resulting in a positive frequencydependent transmission bias (Cavalli-Sforza \& Feldman, 1981). Negative frequency dependence can also alter the extent of diffusion (Laland, 1992). For example, as a foraging innovation becomes more common, competition for the food produced by the innovation may increase, and individuals may become increasingly likely to revert to their original behavior.

Directed social learning. In the study of animal movements, the term diffusion frequently has an implied random element, with movements being modeled using random walk theories taken from the diffusion of inorganic particles (Okubo \& Levin, 2001). In social learning theory, too, the course of transmission of acquired information is usually assumed to be random, an assumption that is frequently violated. Coussi-Korbel and Fragaszy (1995) have suggested that animals are likely to attend to and learn from certain individuals in preference to others, a phenomenon they refer to as directed social learning. This hypothesis has received considerable support, with such variables as familiarity, sex, age, matrilineal relatedness, social rank, foraging history, and motivational state influencing both who innovates and who learns from whom (Carlier \& Lefebvre, 1997; Lachlan et al., 1998; Nicol \& Pope, 1999; Reader \& Laland, 2000, 2001; Swaney, Kendal, Capon, Brown, \& Laland, 2001; Tanaka, 1998). Individuals may also use such cues as demonstrator health or success to bias their choices of whom to learn from (Boyd \& Richerson, 1985). Information may flow preferentially through certain subsections of animal populations as a result of both the nonrandom associations individuals form and the fact that individualscan differ in their propensities to innovate or learn from others.

Directed social learning may result in a step-shaped diffusion curve (Kendal, 2003; Reader, 2000). For example, an innovation may spread rapidly within a family group
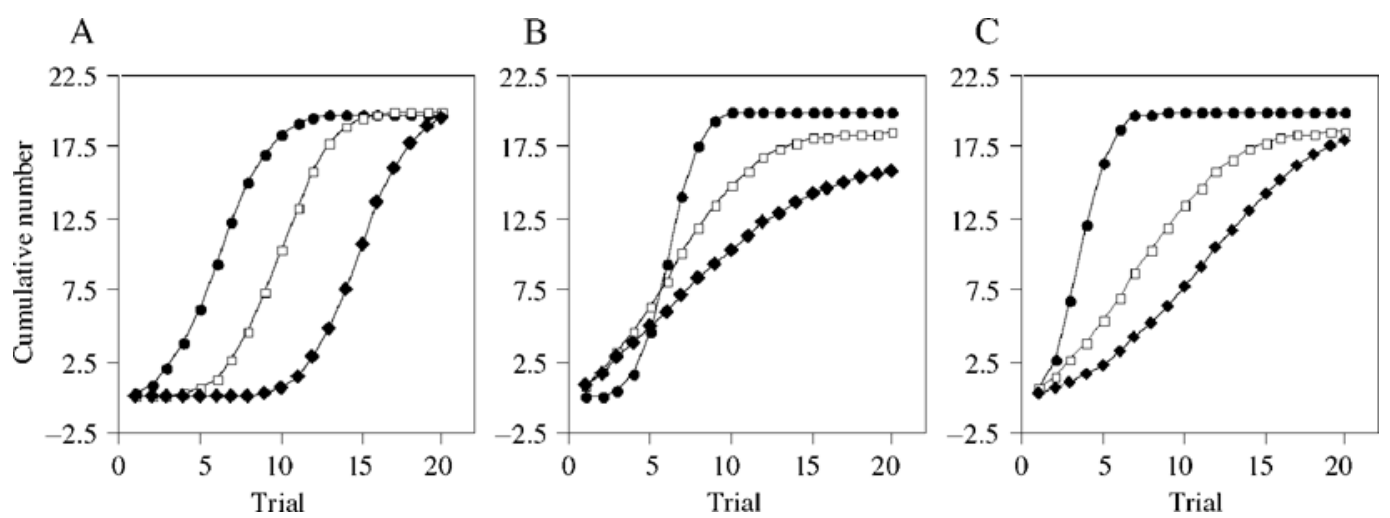

Figure 2. Cumulative plots of the number of individuals learning a task where all learning is asocial and individuals act independently but individual variation in learning performance is normally distributed. (A) Mean number of trials to learn the task increased with the standard deviation held constant. (B) Standard deviation increased with the mean held constant. (C) Mean and standard deviation increased together. All populations are of 20 individuals. Plots are calculated from the cumulative plot of the normal distribution. 
but be transmitted slowly between family groups, as in the spread of butterbur eating in greylag geese (Fritz, Bisenberger, \& Kotrschal, 2000; Kendal, 2003). Figure 1E illustrates this possibility, where the spread of the innovation follows a sigmoidal curve within each subsection of the group. The underlying frequency distribution is bimodal. A bimodal distribution could result from population segregation, a mixture of learning processes (e.g., social learners may learn rapidly and asocial learners slowly, or vice versa), or differences in learning performance (e.g., females may learn a foraging task more rapidly than males; Reader \& Laland, 2000). A cumulative plot of a bimodal distribution resembles the curve produced by a hyperbolic sine function, especially if the beginning of the diffusion is subject to a floor effect (discussed below), if some individuals never acquire the behavior, or if the final phase of the diffusion is not recorded (Reader, 2000). This may provide a theoretical explanation for the success of the hyperbolic sine in fitting a number of cultural transmission data sets (Lefebvre, 1995a, 1995b; see below).

\section{Logistic Biological Models Other Than Cultural Transmission}

A number of biological processes have been predicted to result in S-shaped curves. Indeed, much of the theory behind transmission dynamics models was developed from population genetics, epidemiological, and population growth models that also utilize the logistic (Boyd \& Richerson, 1985; Cavalli-Sforza \& Feldman, 1981; Laland, 1992). Mathematical theories formulated for the number of individuals carrying an infectious disease, the proportion carrying an advantageous mutation, or the number of individuals who have adopted an innovation are formally identical (Cavalli-Sforza \& Feldman, 1981; for details of the models, see Emlen, 1984; Gurney \& Nisbet, 1998; Hastings, 1997; Hutchinson, 1978; Maynard Smith, 1989; Murray, 2002). Although the time scales of these processes may be quite different, these theories should not be dismissed as alternative explanations to cultural transmission for a sigmoid diffusion curve. For example, in a long-lived species, it might be clear that population growth cannot explain a rapid increase in the frequency of a particular behavior pattern. Population growth would also contravene the theoretical assumption of a closed population. However, populations of prey or parasites may change more rapidly, and these changes may be responsible for alterations in behavior in the long-lived species.

Asocial learning and individual variation. If individual variation in learning performance is normally distributed, the spread of an innovation through a population of asocial learners could also be characterized by an acceleratory curve, since a cumulative plot of the normal distribution is sigmoidal (Figure 1A; Day, Kendal, \& Laland, 2001; Laland \& Kendal, 2003; Lefebvre, 1995a; Reader, 2000; but see Kendal, 2003). The point is further emphasized in Figure 2, which illustrates cumulative plots of various normal distributions that vary with respect to means and standard deviations. The curves range in appearance from highly sigmoidal to almost linear. Moreover, when some individuals never learn the innovation or the experiment ends before all the individuals have learned it, as in many studies of animal populations, the sigmoidal diffusion curve for asocial learners may lack a tail, resembling a positive exponential. Thus, a sigmoidal or positive exponential cumulative curve can be predicted to result from both social learning and asocial learning processes.

In the asocial learning field, learning and memory data are commonly presented as learning curves, formed by plotting the proportion of responses at each trial for a group of subjects (Hartz, Ben-Shahar, \& Tyler, 2001). Differences in the shapes of learning curves have been interpreted in terms of an underlying process (Macintosh, 1983; Riddell \& Corl, 1977). Such curves may take a sigmoid shape; indeed, Hartz et al. (2001) have interpreted this shape in terms of within-individual variation in responsiveness to a task and have noted that the logistic curve "serves as a model for learning" (p. 186). In limited circumstances, the shape of a learning curve may influence that of a diffusion curve. For example, consider the adoption of a novel food. Individuals choosing between a novel and a familiar food may initially eat the novel food rarely, and then increasingly often, according to a sigmoid learning curve. A researcher sampling once per day may observe $20 \%$ of the group eating the novel food on Day 1 and $50 \%$ on Day 3, an apparent increase in the number of individuals eating the new food. However, such a finding may merely represent an increase in the probability of observing individuals eating the novel food, because each individual is eating the novel food more often. Tracking individual behavior would alleviate this problem. Sigmoidal curves may thus result from asocial learning in isolation as a consequence of both within-individual and between-individual variation.

\section{Empirical Evidence}

The ideal diffusion data for testing the predictions of social learning models would be those from replicate populations, with all candidate transmission processes experimentally isolated and established. Such data would be quite a task to gather, and it might be difficult experimentally to separate asocial learning and social learning: Asocial learning will be involved to a greater or lesser extent in any instance of social transmission (Fragaszy \& Visalberghi, 2001; Heyes, 1994). I will summarize below relevant data from the literature under three categories: (1) cases of presumed cultural transmission, (2) asocial learning and innovation data, and (3) novelty response data.

Cases of presumed cultural transmission. Table 1 summarizes the work of a number of authors-notably, Lefebvre-in testing diffusion curve models. In the majority of cases, an accelerating function provides the best fit to the data, although the logistic provides the best fit in only a minority of accelerating cases. Most of the 





data were collected observationally, which means that the learning process remains controversial (Galef, 1992). If evidence for cultural transmission (independent of the analysis of diffusion curves) is not robust for a particular study, the study cannot be used to test the prediction that an acceleratory diffusion curve is a reliable indicator of cultural transmission. For example, the spread of milk bottle opening across the United Kingdom is often regarded as a classic case of social transmission, although the original investigators were cautious in their interpretation of the process of diffusion (Fisher \& Hinde, 1949; Hinde \& Fisher, 1951, 1972). Their caution was justified. Experiments on titmice and chickadees have demonstrated that the rate of spontaneous opening of milk bottles may be quite high (Kothbauer-Hellmann, 1990; Sherry \& Galef, 1984, 1990), and analyses of geographical spread have suggested many independent origins of the behavior (Lefebvre, 1995b). Ingram (1998) has argued that the spread of the behavior could have more to do with the introduction of a new type of milk bottle than with spread of an innovation from a single origin. It seems likely that the spread of milk bottle opening was due to many independent innovations, combined with social learning within a locality.

Experimental studies allow a more certain identification of social learning as the transmission process. However, to my knowledge, in only three experimental studies have the mathematics of diffusion curves been examined. Cloutier et al. (2002) studied learning of cannibalistic behavior in chickens, using demonstrators trained to eat blood from a membrane-covered dish. The demonstrators were placed into flocks of naive birds (Condition 1), or the naive flock could observe demonstrators through a wire mesh (Condition 2). The observers were

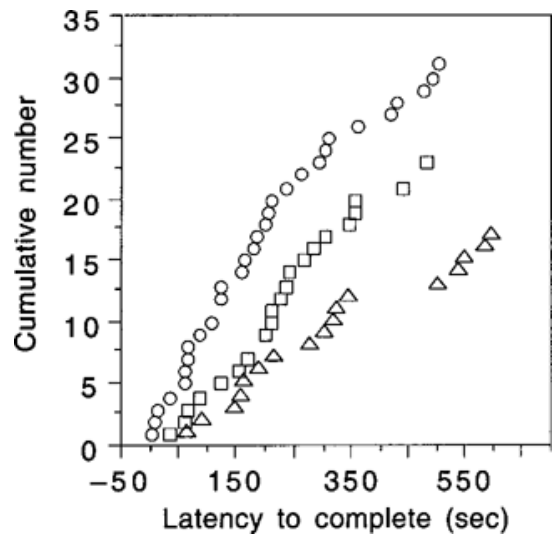

Figure 3. Cumulative plot of the number of guppies solving simple maze tasks to reach a food reward. The data are the latencies of the first fish in a group to complete a task, taken from Laland and Reader (1999). The three tasks were swimming through a hole in an opaque partition (circles), swimming up a tunnel (squares), and swimming down a tunnel (triangles). All sex and age classes are pooled; differences between sexes or ages may affect the shape of the curve. tested in pairs after each demonstration session. A sigmoidal function provided the best fit to Condition 1 data, but a polynomial (that, on inspection, appears to be linear or decelerating) provided the best fit to social transmission in Condition 2. These findings are consistent with kinetic models of social learning (Cavalli-Sforza \& Feldman, 1981), since only in Condition 1 could the number of demonstrators increase as individuals learned the task. In Condition 2, observers that had learned the task could not act as additional demonstrators, since they were separated from the test apparatus by wire mesh during the demonstration sessions.

Langen (1996) and Lefebvre (1986) introduced trained demonstrators into captive and free-living groups of birds. In neither study were diffusion curves clearly acceleratory. The increase in the cumulative number of door-opening white-throated magpie jays (Langen, 1996) resembled an exponential curve, but the exponential model did not provide a significantly better fit than a linear model. In the case of pigeons piercing paper-covered food wells (Lefebvre, 1986), the results were mixed, with the logistic providing the best fit to one data set, but decelerating functions providing the best fit to two others.

Asocial learning data and innovation data. Studying asocial learning without the possibility of social learning raises problems when animals are housed in groups. To evaluate the predictions of theoretical diffusion models, the process underlying diffusion must be known. Thus, in this and the next section, I have compiled data from a variety of sources in which, as far as possible, independent measures of individual performance were taken. It may seem counterintuitive to use data from individually tested animals for constructing diffusion curves, but a cumulative "diffusion curve" can be produced by assuming that the speed of task acquisition would be the same whether individuals were housed together or apart. Individuals that did not complete the task were not included in the analyses. In each of Figures 3-5, animals were presented with novel foraging tasks, and their times to complete the tasks were measured. In the case of the guppies (Figure 3; see Laland \& Reader, 1999), the latencies are those of the first fish in a group to complete a task. In the case of the Carib grackles (Reader \& Lefebvre, unpublished data), the birds were housed individually and were presented with tasks of varying difficulty 10 times, each trial lasting a maximum of $300 \mathrm{sec}$. The same birds were presented with three social learning tasks, with performance determined in a 60 -sec trial after each of 10 demonstration sessions. The subjects in the social learning task were tested individually, so individual variation in social learning performance was examined.

Two points are clear from an inspection of Figures 3-5 (formal curve-fitting was not attempted for the reasons outlined in the Practical Considerations section, below). First, individual differences are pervasive, even in social learning tasks (Figure 5). Second, decelerating curves tend to characterize most of the observations. Such curves 

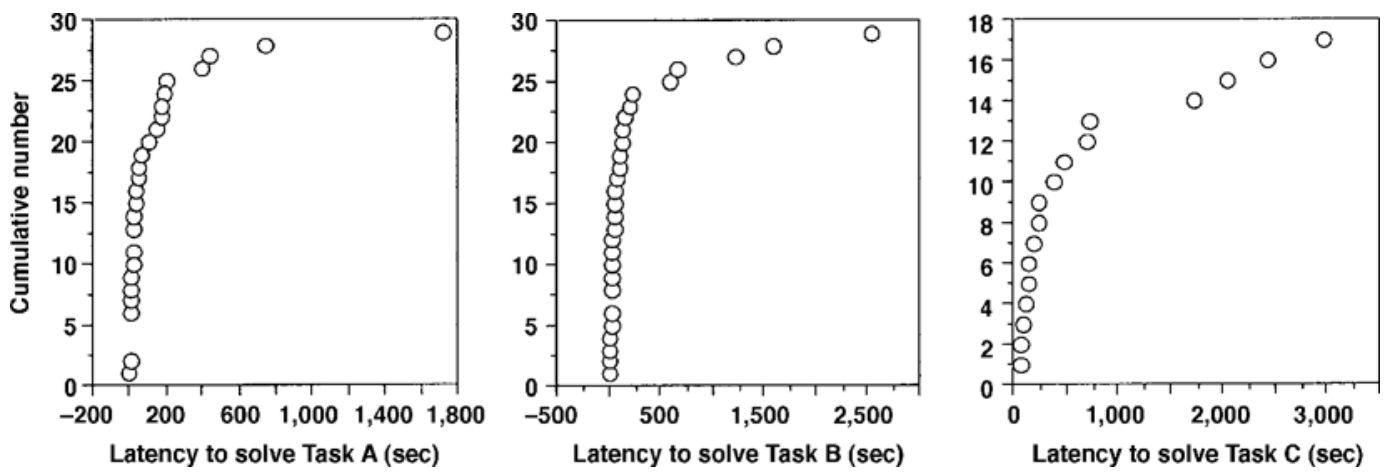

Figure 4. Cumulative plot of the number of individuals solving three asocial learning tasks (Reader \& Lefebvre, unpublished data). Wild-caught Carib grackles were presented individually with foraging tasks of varying difficulty (the difficulty increased from Task A to $\mathrm{C}$, judging by the time pilot birds took to complete them).

could be regarded as support for the hypothesis that decelerating curves characterize asocial learning processes. However, floor effects provide an alternative explanation. A floor effect could result from a very easy task, so that many individuals acquire the solution rapidly and no variation between individuals can be discerned. Where many individuals solve a task rapidly and a few individuals solve it slowly, the underlying frequency distribution will resemble a highly left-skewed normal distribution that can produce a decelerating cumulative curve. It is also notable from Figure 5 that quite different diffusion curves are observed for the three social learning tasks, despite the fact that tests were run on consecutive days with similar tasks and the same observers, demonstrators, and hunger levels. Although the number of birds tested with the social learning tasks was small, this variability does suggest that inferring cognitive process from cumulative curves will be a challenge.

Novelty responses. Novelty responses are likely to be central to the inception and spread of innovations (Greenberg, 2003; Reader \& Laland, 2003). Thus, individual variation in response to novel situations could be re- flected in the shapes of diffusion curves. Figures 6-9 take an identical approach to that in Figures 3-5, plotting cumulative number of individuals completing a task against latency to complete that task. The tasks involved individuals' reactions to novel objects, spaces, and foods, often by presenting the same animals with a battery of tests. Decelerating cumulative curves seem to characterize individual variations in time to contact novel objects, enter novel spaces, and eat novel and familiar foods in grackles, tits, and guppies (Figures 6 and 7). In the case of the guppies (Figure 7), there is a clear bimodal frequency distribution (Budaev, 1997). The distribution of approach times in the juvenile tits was also bimodal, in the sense that most individuals approached the object either very soon or not at all (Verbeek, Drent, \& Wiepkema, 1994).

In Greenberg's studies (1984a, 1984b, 2003), novelty responses were assessed by presenting familiar foods alongside novel objects. The same birds were presented with the various novel objects, and it is notable that the resulting diffusion curves are quite variable (Figure 8). The bay-breasted warbler is more opportunistic in its for-
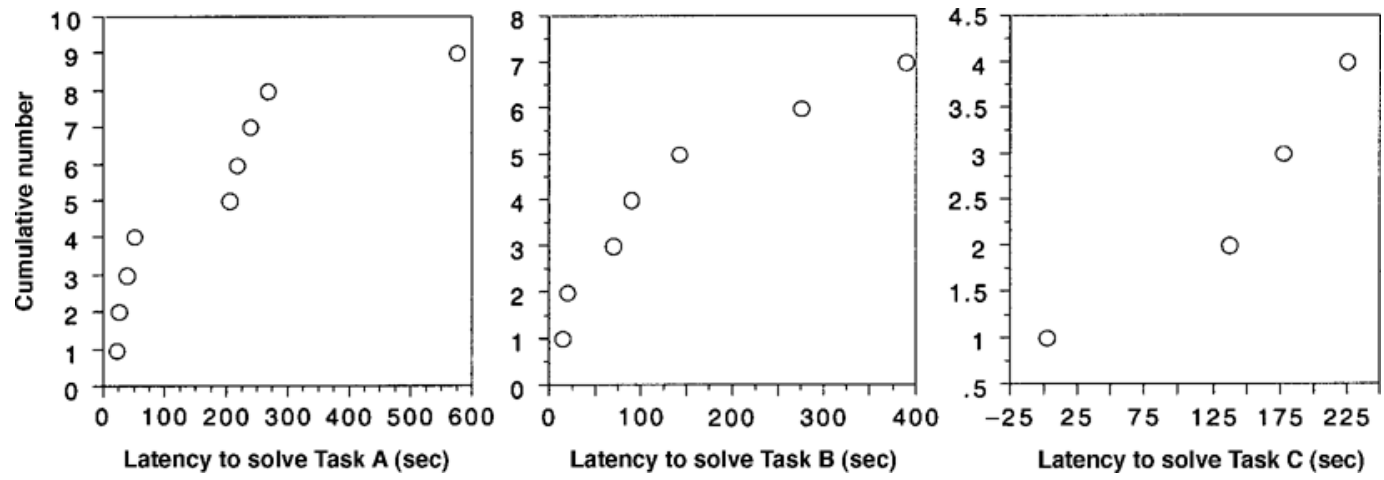

Figure 5. Cumulative plot of the number of individuals solving three social learning tasks (Reader \& Lefebvre, unpublished data). Wild-caught Carib grackles were individually paired with a demonstrator trained to perform various foraging tasks. 

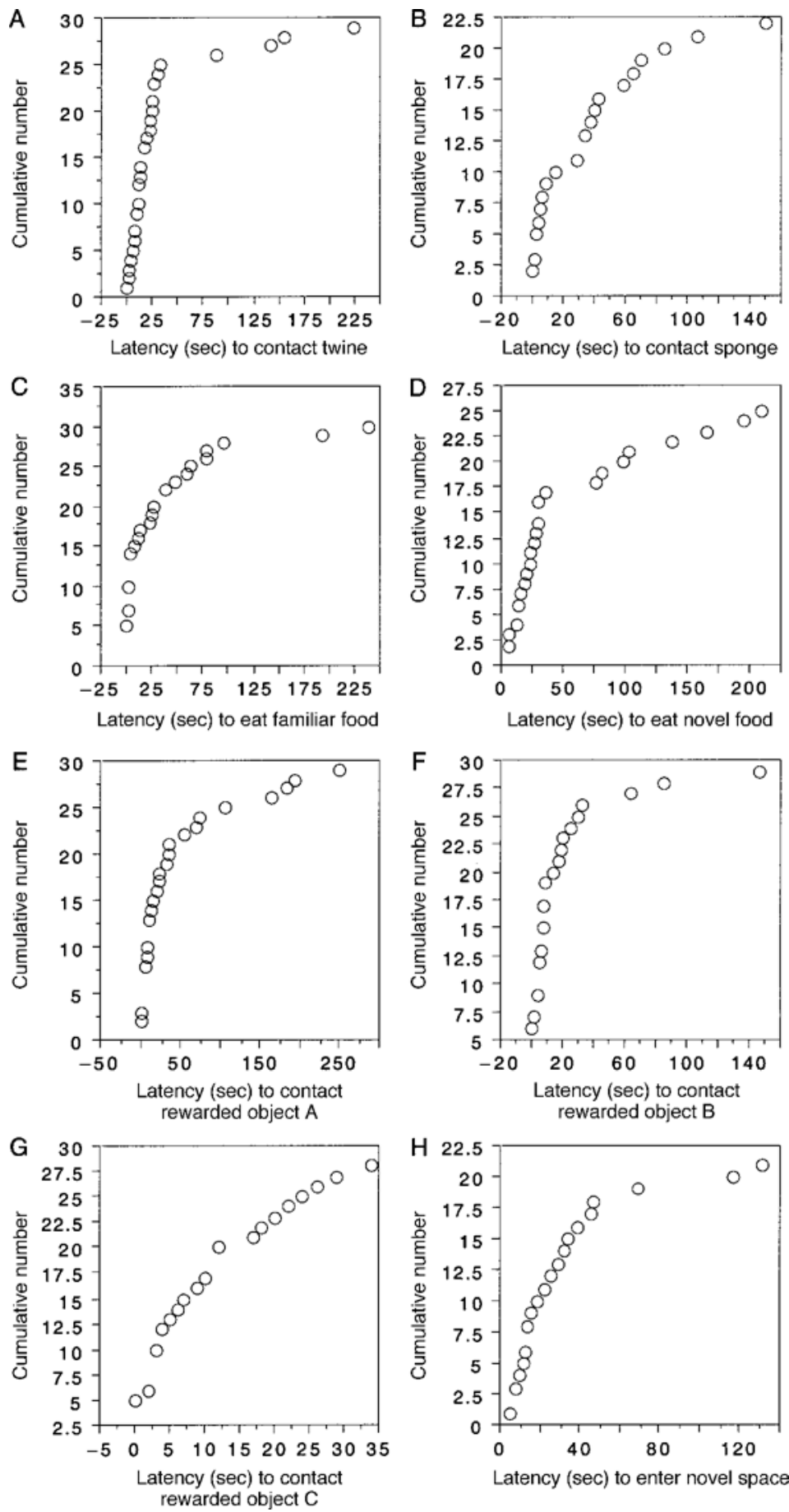

Figure 6. Cumulative plots of number of individuals responding to various novel tasks (Reader \& Lefebvre, unpublished data). Wild-caught Carib grackles were tested in individual aviaries with novel objects (A and B), familiar (C) and novel (D) foods, novel objects containing a visible food reward (E, F, and $G)$, and a novel space (H).

aging behavior than the congeneric chestnut-sided warbler (Greenberg, 1984a), and this difference seems to be reflected in the bay-breasted warblers' more rapid approach to novel objects. Here, comparison between the two diffusion curves is particularly informative. Wild birds presented with novel-colored foods (Marples \& Kelly, 1999; Marples, Roper, \& Harper, 1998) were extremely variable in their responses, with some accepting 
A

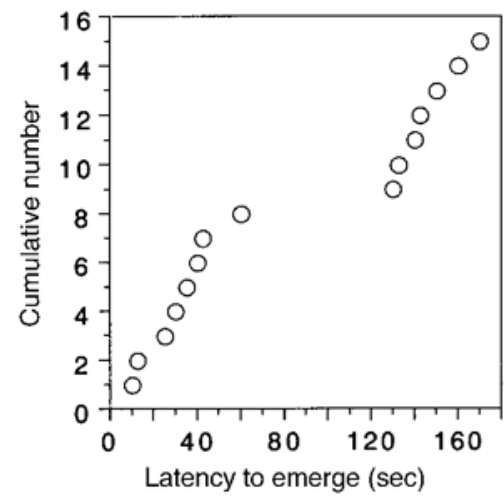

B

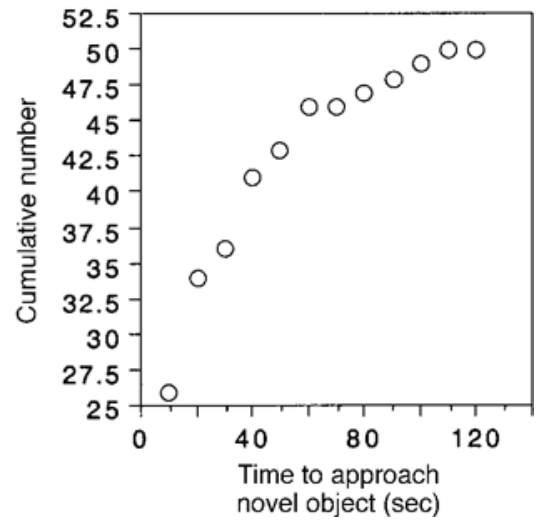

Figure 7. Cumulative plot of the number of guppies entering a novel space (A; data from Budaev, 1997) and the number of male great tits approaching a novel object, a penlight battery (B; data from Verbeek, Drent, \& Wiepkema, 1994).

novel-colored bait immediately, whereas others took hundreds of trials (Figure 9). Such individual variation is widespread (Galef \& Wright, 1995) and has been shown to be heritable (Marples \& Brakefield, 1995).

\section{Practical Considerations}

Thus, the match between theoretical prediction and empirical data is rather mixed. Several practical considerations may affect the shape of the diffusion curve, and it may be hard to distinguish between functions on the basis of curve-fitting to real data (Laland et al., 1996). In observational studies, the beginning of diffusion could easily be missed, potentially obscuring an initial acceleratory phase. For example, a novel behavior may have been performed infrequently and thus overlooked or may have emerged timed with a seasonal food source and been performed the year before observations began. In experimental studies, floor effects could obscure the initial acceleratory phase. The terminal phase of a diffusion may also be missed-for example, when an experiment or a field season terminates. In several cases described in Table 1, the spread of innovations was very slow, perhaps making it difficult to distinguish slow learners from those that will never learn. In long-term data sets, interpretation of data will also be complicated by births, deaths, and individual movements. The proportion of the population exhibiting an innovation can be examined and plotted, but it is not clear how applicable the predictions of theoretical models are to such curves. In general, cumulated frequencies are more likely to yield accelerating functions than are proportion data since, by definition, cumulative curves cannot decrease (Lefebvre, 1995a). Observational studies of acquired behavior patterns may also be biased by temporal changes in human interest in a particular behavior pattern (Lefebvre, 1995b).

Relatively simple variables, such as testing schedules, may also affect observed diffusion curves. In many stud- ies, animals are presented with tasks repeatedly over several trials. However, repeated presentations can produce results qualitatively quite different from those produced by a single lengthy presentation. Repeated presentation may rekindle an animal's interest in a task or delay approach by neophobicindividuals. In addition, unless trials are held at the same time each day, with subjects in the same motivational state, time will act as a confounding factor, clouding determination of "true" diffusion curves. Hunger levels may vary throughout the day, and novel behaviors may vary in their profitability depending on variations in the availability of alternative food sources. Individuals may not perform a behavior pattern they have acquired. Periods of sleep may affect both hunger levels and performance of learned tasks (Dave, Yu, \& Margoliash, 1998; Fischer, Hallschmid, Elsner, \& Born, 2002). An innovation may itself also have a confounding effect if, for example, spread of an acquired behavior increases the rate of population growth. Even more trivial factors, such as periods of bad weather, could make interpretation of a diffusion curve difficult. If individuals cannot perform an acquired behavior pattern, they may forget it. Alternatively, climatic changes could favor innovation (Reader \& Laland, 2003). In the laboratory, it may be appropriate to examine a trait-adoption curve, a curve plotted from the beginning of task exposure (Kendal, personal communication, February 28, 2003). A diffusion curve begins with the first innovator, whereas an adoption curve would also include information on the time taken for the innovator to acquire the novel behavior.

\section{Alternative Approaches to Studying Animal Social Learning}

The advantage to using the shape of the diffusion curve as a diagnostic of underlying process is that it can be applied to observational data where experimental manipulations are not possible. However, alternative approaches may be necessary, given that theoretical cultural trans- 

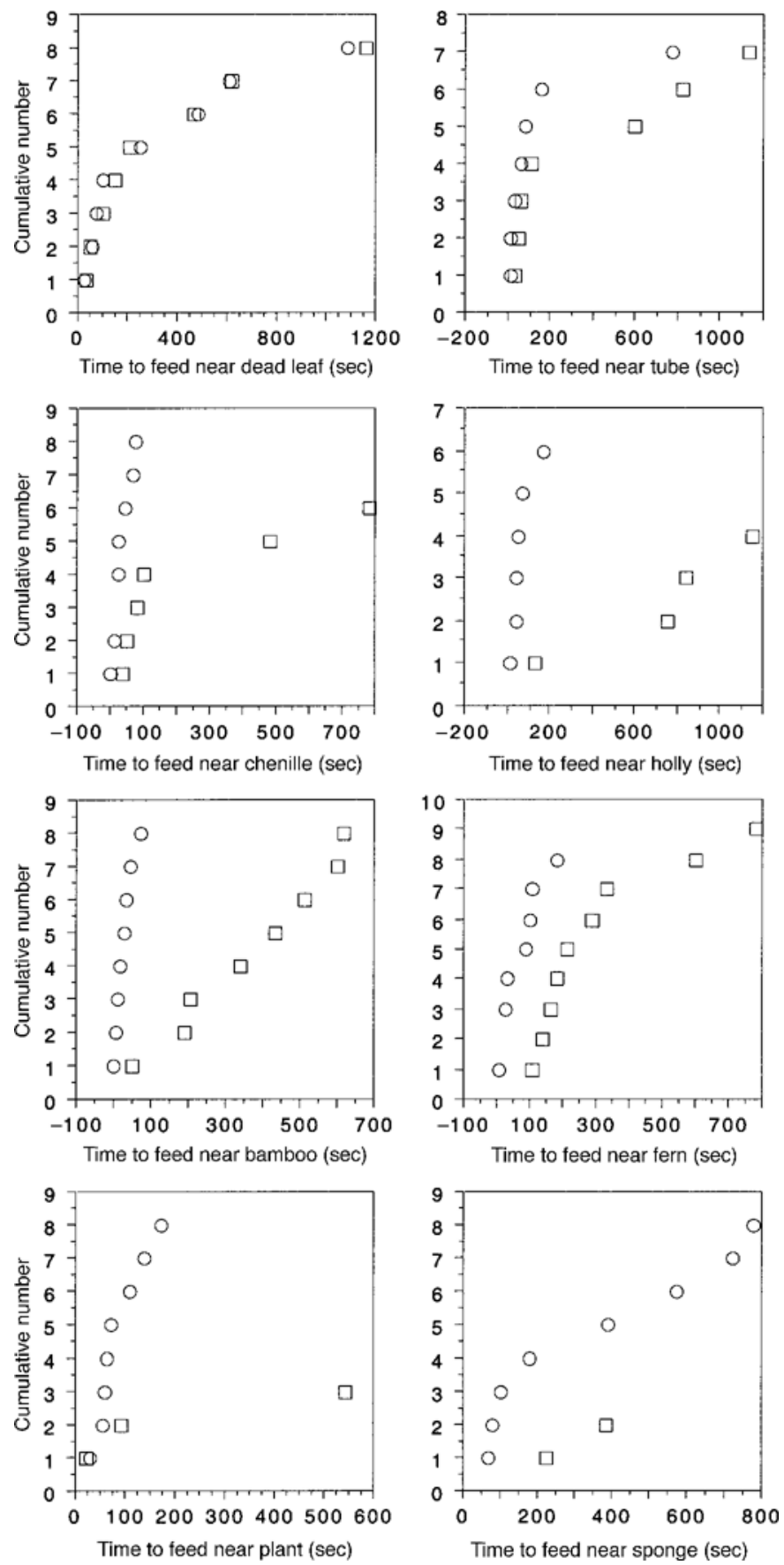

Figure 8. Cumulative plot of number of individuals feeding alongside various novel objects. Circles, bay-breasted warblers; squares, chestnutsided warblers. Data are from Greenberg $(1984 \mathrm{a}, 1984 \mathrm{~b})$. The baybreasted warbler is the more opportunistic species (Greenberg, 1984a).

mission models give mixed predictions, other models of biological processes also predict sigmoidal curves, and the empirical data do not give unqualified support for the sigmoid diffusion curve as a diagnostic of social learning.

The development of new methods and models or the application of existing models from other fields may aid in the determination of learning processes in the field. For example, the wave-of-advance model can be used to examine the spatial spread of innovations, plotting the spatial distance from the proposed origin of the innovation against time (Cavalli-Sforza \& Feldman, 1973; Lefebvre, 1995b). In the case of milk-bottle opening birds, the 
A

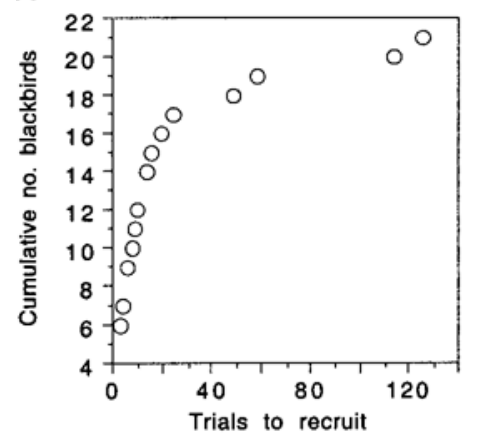

D

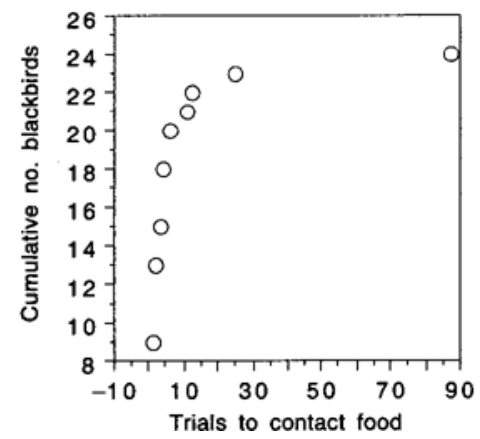

B

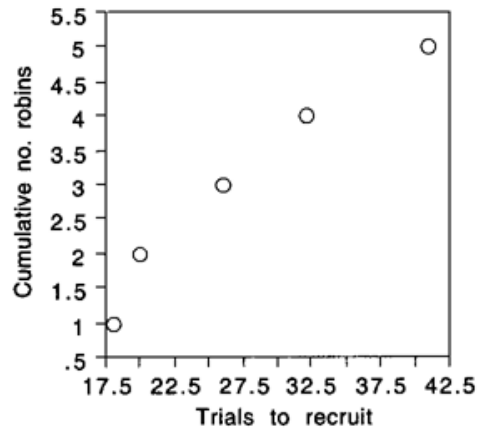

E

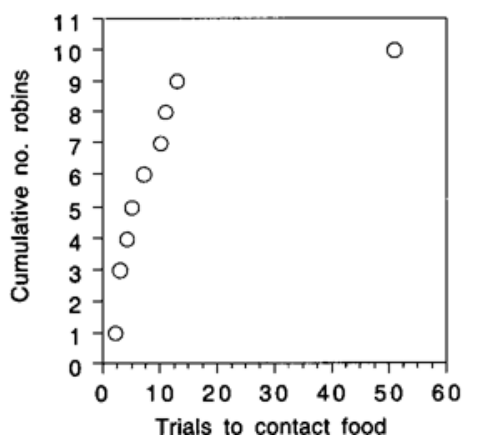

C

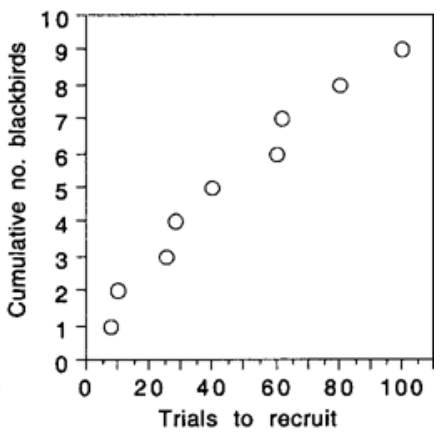

○ 1

Figure 9. Cumulative plots of the number of birds incorporating novel foods into their diets (A, B, and C) or contacting the novel food for the first time (D and $E$ ). For panels A, B, D, and E, the data are from Marples, Roper, and Harper (1998). For panel $\mathrm{C}$, the data are from Marples and Kelly (1999,Study H). Blackbirds and robins form territorial pairs, and the food was presented within each pair's territory, so any potential social influence on the eating of novel food was restricted. Recruitment was defined as consumption of the food on three successive trials. Tests with different colors were treated as independent.

wave-of-advance model was rejected, since the data were inconsistent with the spread of the innovation from a single origin (Lefebvre, 1995b). (Note that a strong positive correlation between distance and the time of new occurrences does not in itself provide support for social transmission, since innovations could also spread from a single origin as a consequence of the dispersal of the individuals carrying the innovation [Cavalli-Sforza \& Feldman, 1973; Lefebvre, 1995b; van Schaik, 2002]). A second potential approach, the cue reliability approach (Dewar, 2003, 2004), involves examining putative traditions where an ecological explanation for population differences seems likely. Third, statistical methods are available to test for nonindependence in behavior and for temporal associations (Sokal \& Rohlf, 1995), and although this may not eliminate all alternative explanations, these could be applied to observational social learning studies. Finally, mathematical models of transmission dynamics have begun to specifically address spatial diffusion and to incorporate experimental findings from animal social learning, making novel predictions (Kendal, 2003; Laland et al., 1996). The heuristic power of mathematical models lies not only in making testable predictions, but also in formally setting out the pertinent assumptions for empirical attention (Cavalli-Sforza \& Feldman, 1981).
Learning processes in the field can also be examined experimentally, either through field experiments (e.g., Langen, 1996; Lefebvre, 1986; Reader, Kendal, \& Laland, 2003; Warner, 1990a, 1990b; Wilkinson \& Boughman, 1999) or by bringing the behavior into the laboratory (e.g., Galef, 1980; Terkel, 1996). Laboratory social learning studies can address both learning on the part of a single observer and the transmission of behaviors through groups (e.g., Curio, Ernst, \& Vieth, 1978; Galef \& Allen, 1995; Laland \& Plotkin, 1992; Laland \& Williams, 1997). Careful field observation for determining population differences in behavioral repertoires can provide evidence for cultural transmission beyond that given from diffusion curves (e.g., van Schaik et al., 2003; Whiten et al., 1999), although alternative explanations for population differences, such as genetic and ecological differences, may be difficult to exclude (Dewar, 2003; Galef, 2003; Roper, 1986).

\section{Conclusion}

Theoretical models suggest that sigmoidal diffusion curves could result for several reasons, including both social and asocial learning. Empirical data show that individual variability, rarely incorporated into theoretical models, is pervasive. Thus, linear diffusion curves may not be an appropriate null hypothesis. The majority of 
the putative cases of cultural transmission reviewed were characterized by accelerating curves, whereas curves describing asocial learning and novelty responses tended to be decelerating. This would support the hypothesis that the shape of the diffusion curve can be informative in identifying social learning. However, the shapes of the curves were quite variable and empirical diffusion curves are subject to a number of practical concerns. The view that the speed and temporal dynamics in which novel behavior diffuses can be treated as a simple diagnostic of the underlying learning process should be treated with caution. Evidence for social learning in the field can come instead from field experiments, laboratory study of the processes underlying the acquisition of behavioral patterns observed in the wild, and systematic analysis of between-population variation in behavioral repertoires.

\section{REFERENCES}

AKAIKE, H. (1973). Information theory and an extension of the maximum likelihood principle. In B. N. Petrov \& F. Csáki (Eds.), 2nd International Symposium on Information Theory (pp. 267-281). Budapest: Akademiai Kiado.

AKAIKE, H. (1978). A Bayesian analysis of the minimum AIC procedure. Annals of the Institute of Statistical Mathematics, 30, 9-14.

AzUMA, S. (1973). Acquisition and propagation of food habits in a troop of Japanese macaques. In C. R. Carpenter (Ed.), Behavioral regulators of behavior in primates (pp. 284-292). Lewisburg, PA: Bucknell University Press.

BeCK, M., \& GAlEF, B. G., JR. (1989). Social influences on the selection of a protein-sufficient diet by Norway rats (Rattus norvegicus). Journal of Comparative Psychology, 103, 132-139.

BOYD, R., \& RICHERSON, P. J. (1985). Culture and the evolutionary process. Chicago: University of Chicago Press.

Budaev, S. V. (1997). "Personality" in the guppy (Poecilia reticulata): A correlational study of exploratory behavior and social tendency. Journal of Comparative Psychology, 111, 399-411.

CARLIER, P., \& LefebVRe, L. (1997). Ecological differences in social learning between adjacent, mixing populations of Zenaida doves Ethology, 103, 772-784.

CAVAlli-SForza, L., \& Feldman, M. W. (1973). Models for cultural inheritance: I. Group mean and within group variation. Theoretical Population Biology, 4, 42-55.

CAVAlli-SForza, L., \& Feldman, M. W. (1981). Culturaltransmission and evolution: A quantitative approach. Princeton, NJ: Princeton University Press.

Cloutier, S., Newberry, R. C., Honda, K., \& Alldredge, J. R. (2002). Cannibalistic behaviour spread by social learning. Animal Behaviour, 63, 1153-1162.

Coussi-Korbel, S., \& Fragaszy, D. M. (1995). On the relation between social dynamics and social learning. Animal Behaviour, 50, 1441-1453.

CURIO, E., ERnST, U., \& VIETH, W. (1978). The adaptive significance of avian mobbing: II. Cultural transmission of enemy recognition in blackbirds: Effectiveness and some constraints. Zeitschrift für Tierpsychologie, 42, 184-202.

Dave, A. S., Yu, A. C., \& Margoliash, D. (1998). Behavioral state modulation of auditory activity in a vocal motor system. Science, 282, 2250-2254.

DAY, R. L., KENDAL, J. R., \& LALAND, K. N. (2001). Validating cultural transmission in cetaceans. Behavioral \& Brain Sciences, 24, 330331.

Day, R. L., MacDonald, T., Brown, C., LALAND, K. N., \& ReAder, S. M. (2001). Interactions between shoal size and conformity in guppy social foraging. Animal Behaviour, 62, 917-925.

DEWAR, G. (2003). The cue reliability approach to social transmission designing tests for adaptive traditions. In D. M. Fragaszy \& S. Perry
(Eds.), The biologyof traditions: Models and evidence (pp. 127-158). Cambridge: Cambridge University Press.

DEWAR, G. (2004). Social and asocial cues about new food: Cue reliability influences intake in rats. Learning \& Behavior, 32, 82-89.

EMLEN, J. M. (1984). Population biology: The coevolution of population dynamics and behavior. New York: Macmillan.

Fischer, S., HAllschmid, M., ElSNER, A. L., \& Born, J. (2002). Sleep forms memory for finger skills. Proceedings of the National Academy of Sciences, 99, 11987-11991.

Fishe R, J., \& HindE, R. A. (1949). The opening of milk bottles by birds. British Birds, 42, 347-357.

Fragaszy, D. M., \& VisAlberghi, E. (2001). Recognizing a swan: Socially-biased learning. Psychologia, 44, 82-98.

Fritz, J., Bisenberger, A., \& Kotrschal, K. (2000). Stimulus enhancement in greylag geese: Socially mediated learning of an operant task. Animal Behaviour, 59, 1119-1125.

GALEF, B. G., JR. (1980). Diving for food: Analysis of a possible case of social learning in wild rats (Rattus norvegicus). Journal of Comparative \& Physiological Psychology, 94, 416-425.

GALEF, B. G., JR. (1990). Tradition in animals: Field observations and laboratory analyses. In M. Bekoff \& D. Jamieson (Eds.), Interpretation and explanation in the study of behavior: Vol. 1. Interpretation, intentionality, and communication (pp. 74-95). Boulder, CO: Westview.

Galef, B. G., JR. (1992). The question of animal culture. Human Nature, 3, 157-178.

GALEF, B. G., JR. (2001). Where's the beef? Evidence of culture, imitation, and teaching in cetaceans? Behavioral \& Brain Sciences, 24, 335 .

GAlef, B. G., JR. (2003). Social learning: Promoter or inhibitor of innovation? In S. M. Reader \& K. N. Laland (Eds.), Animal innovation (pp. 137-154). Oxford: Oxford University Press.

Galef, B. G., JR., \& Allen, C. (1995). A new model for studying behavioural traditions in animals. Animal Behaviour, 50, 705-717.

GALEF, B. G., JR., \& Wright, T. J. (1995). Groups of naive rats learn to select nutritionally adequate foods faster than do isolated naive rats. Animal Behaviour, 49, 403-409.

GiraldeAU, L.-A., \& CARACO, T. (2000). Social foraging theory. Princeton, NJ: Princeton University Press.

Giraldeau, L.-A., Caraco, T., \& VAlone, T. J. (1994). Social foraging: Individual learning and cultural transmission of innovations. Behavioral Ecology, 5, 35-43.

GiRAldEAU, L.-A., \& LefeBVRE, L. (1987). Scrounging prevents cultural transmission of food-finding behaviour in pigeons. Animal Behaviour, 35, 387-394.

GREENBERG, R. (1984a). Differences in feeding neophobia in the tropical migrant wood warblers Dendroica castanea and D. pensylvanica. Journal of Comparative Psychology, 98, 131-136.

GREENBERG, R. (1984b). Neophobia in the foraging-site selection of a neotropical migrant bird: An experimental study. Proceedings of the National Academy of Sciences, 81, 3778-3780.

GREENBERG, R. (2003). The role of neophobia and neophilia in the development of innovative behaviour of birds. In S. M. Reader \& K. N. Laland (Eds.), Animal innovation (pp. 175-196). Oxford: Oxford University Press.

Gurney, W. S. C., \& Nisbet, R. M. (1998). Ecological dynamics. Oxford: Oxford University Press.

Hartz, S. M., Ben-Shahar, Y., \& Tyler, M. (2001). Logistic growth curve analysis in associative learning data. Animal Cognition, 4, 185189.

Hastings, A. (1997). Population biology: Concepts and models. New York: Springer-Verlag.

HAUSER, M. D. (1988). Invention and social transmission: New data from wild vervet monkeys. In R. W. Byrne \& A. Whiten (Eds.), Machiavellian intelligence: Social expertise and the evolution of intellect in monkeys, apes and humans (pp. 327-343). Oxford: Oxford University Press.

HEYES, C. M. (1994). Social learning in animals: Categories and mechanisms. Biological Reviews, 69, 207-231.

HindE, R. A., \& Fisher, J. (1951). Further observations on the opening of milk bottles by birds. British Birds, 44, 393-396.

Hinde, R. A., \& Fisher, J. (1972). Some comments on the republica- 
tion of two papers on the opening of milk bottles by birds. In P. H Klopfer \& J. P. Hailman (Eds.), Function and evolution of behavior: An historical sample from the pens of ethologists (pp. 377-378). Reading, MA: Addison-Wesley.

HufFMAN, M. A., \& HiRATA, S. (2003). Biological and ecological foundations of primate behavioral tradition. In D. M. Fragaszy \& S. Perry (Eds.), The biology of traditions: Models and evidence (pp. 267-296). Cambridge: Cambridge University Press.

Hutchinson, G. E. (1978). An introduction to populationecology. New Haven, CT: Yale University Press.

INGRAM, J. (1998). The barmaid's brain and other strange tales from science. Toronto: Viking.

ITANI, J. (1965). On the acquisition and propagation of a new food habit in the troop of Japanese monkeys at Takasakiyama. In K. Imanishi \& S. A. Altmann (Eds.), Japanese monkeys: A collection of translations (pp. 52-65). Edmonton: University of Alberta Press.

ITANI, J., \& NiSHIMURA, A. (1973). The study of infra-human culture in Japan. In E. W. Menzel (Ed.), Precultural primate behavior (pp. 26 50). New York: Karger.

KAWAI, M. (1965). Newly-acquired pre-cultural behavior of the natural troop of Japanese monkeys on Koshima Islet. Primates, 6, 1-30.

Kendal, J. R. (2003). An investigation into social learning: Mechanisms, diffusion dynamics, functions and evolutionary consequences. Unpublished doctoral thesis, University of Cambridge.

Kothbauer-Hellmann, R. (1990). On the origin of a tradition: Milk bottle opening by titmice. Zoologischer Anzeiger, 225, 353-361.

LACHLAN, R. F., CROOKS, L., \& LALAND, K. N. (1998). Who follows whom? Shoaling preferences and social learning of foraging information in guppies. Animal Behaviour, 56, 181-190.

LALAND, K. N. (1992). A theoretical investigation of the role of social transmission in evolution. Ethology \& Sociobiology, 13, 87-113.

LALAND, K. N., \& KENDAL, J. R. (2003). What the models say about social learning. In D. M. Fragaszy \& S. Perry (Eds.), The biology of tra ditions: Models and evidence (pp. 33-55). Cambridge: Cambridge University Press.

Laland, K. N., \& Plotkin, H. C. (1992). Further experimental analysis of the social learning and transmission of foraging information amongst Norway rats. Behavioural Processes, 27, 53-64.

Laland, K. N., \& Plotkin, H. C. (1993). Social transmission of food preferences among Norway rats by marking of food sites and by gustatory contact. Animal Learning \& Behavior, 21, 35-41.

LALAND, K. N., \& READER, S. M. (1999). Foraging innovation in the guppy. Animal Behaviour, 57, 331-340.

LALAND, K. N., Richerson, P. J., \& Boyd, R. (1996). Developing a theory of animal social learning. In C. M. Heyes \& B. G. Galef, Jr. (Eds.), Social learning in animals: The roots of culture (pp. 129-154). London: Academic Press.

LALAND, K. N., \& Williams, K. (1997). Shoaling generates social learning of foraging information in guppies. Animal Behaviour, $\mathbf{5 3}$ 1161-1169.

LANGEN, T. A. (1996). Social learning of a novel foraging skill by white throated magpie jays (Calocitta formosa, Corvidae): A field experiment. Ethology, 102, 157-166.

LEFE BVRE, L. (1986). Cultural diffusion of a novel food-finding behaviour in urban pigeons: An experimental field test. Ethology, 71, 295-304.

LEFEBVRE, L. (1995a). Culturally-transmitted feeding behaviour in primates: Evidence for accelerating learning rates. Primates, 36, 227 239.

LEFEBVRE, L. (1995b). The opening of milk bottles by birds: Evidence for accelerating learning rates, but against the wave-of-advance model of cultural transmission. Behavioural Processes, 34, 43-53.

LefeBvRe, L., \& GiRAldeAU,L.-A. (1994). Cultural transmission in pigeons is affected by the number of tutors and bystanders present. Animal Behaviour, 47, 331-337.

Lefebvre, L., \& PALAMETA, B. (1988). Mechanisms, ecology and population diffusion of socially learned, food-finding behavior in feral pigeons. In T. R. Zentall \& B. G. Galef, Jr. (Eds.), Social learning: Psychological and biological perspectives (pp. 141-163). Hillsdale, NJ: Erlbaum.

Macintosh, N. J. (1983). General principles of learning. In T. R. Hal- liday \& P. J. B. Slater (Eds.), Animal behaviour: Vol. 3. Genes, development and learning (pp. 149-177). Oxford: Blackwell.

MARPLES, N. M., \& BRAKEFIELD, P. M. (1995). Genetic variation for the rate of recruitment of novel insect prey into the diet of a bird. Biological Journal of the Linnean Society, 55, 17-27.

Marples, N. M., \& Kelly, D. J. (1999). Neophobia and dietary conservatism: Two distinct processes? Evolutionary Ecology, 13, 641-653.

Marples, N. M., Roper, T. J., \& HARPer, D. G. C. (1998). Responses of wild birds to novel prey: Evidence of dietary conservatism. Oikos, 83, 161-165.

MAYNARD SMith, J. (1989). Evolutionary genetics. Oxford: Oxford University Press.

MurRAY, J. D. (2002). Mathematical biologyI: An introduction(3rd ed.). Berlin: Springer-Verlag.

NiCOL, C. J., \& POPE, S. J. (1999). The effects of demonstrator social status and prior foraging success on social learning in laying hens. Animal Behaviour, 57, 163-171.

OKubo, A., \& Levin, S. A. (Eds.) (2001). Diffusion and ecological problems: Modern perspectives (2nd ed.). New York: Springer-Verlag.

PAGEL, M. (1997). Inferring evolutionary processes from phylogenies. Zoologica Scripta, 26, 331-348.

READER, S. M. (2000). Social learning and innovation: Individual differences, diffusion dynamics and evolutionary issues. Unpublished doctoral thesis, University of Cambridge.

ReAdER, S. M., Kendal, J. R., \& LALAND, K. N. (2003). Social learning of foraging sites and escape routes in wild Trinidadian guppies. Animal Behaviour, 66, 729-739.

ReAdER, S. M., \& LALAND, K. N. (2000). Diffusion of foraging innovations in the guppy. Animal Behaviour, 60, 175-180.

Reader, S. M., \& Laland, K. N. (2001). Primate innovation: Sex, age and social rank differences. International Journal of Primatology, 22, 787-805.

READER, S. M., \& LALAND, K. N. (2003). Animal innovation: An introduction. In S. M. Reader \& K. N. Laland (Eds.), Animal innovation (pp. 3-38). Oxford: Oxford University Press.

Rendell, L., \& WhiteheAd, H. (2001). Culture in whales and dolphins. Behavioral \& Brain Sciences, 24, 309-324.

RIDDELL, W. I., \& CORL, K. G. (1977). Comparative investigation of the relationship between cerebral indices and learning abilities. Brain, Behavior \& Evolution, 14, 385-398.

Rogers, E. M. (1995). Diffusion of innovations (4th ed.). New York: Free Press.

ROPER, T. J. (1986). Cultural evolution of feeding behaviour in animals. Science Progress, 70, 571-583.

SHERRY, D. F., \& GAlEF, B. G., JR. (1984). Cultural transmission without imitation: Milk bottle opening by birds. Animal Behaviour, 32, 937-938.

SHERRY, D. F., \& GALEF, B. G., JR. (1990). Social learning without imitation: More about milk bottle opening by birds. Animal Behaviour, 40, $987-989$

SHETTLEWORTH, S. J. (1998). Cognition, evolution, and behaviour. Oxford: Oxford University Press.

SOKAL, R. R., \& RoHLF, F. J. (1995). Biometry (3rd ed.). New York: Freeman.

SugitA, Y. (1980). Imitative choice behavior in guppies. Japanese Psychological Research, 22, 7-12.

SUZUKI, A. (1965). An ecological study of wild Japanese monkeys in snowy areas focused on their food habits. Primates, 6, 31-72.

Swaney, W., Kendal, J., Capon, H., Brown, C., \& Laland, K. N. (2001). Familiarity facilitates social learning of foraging behaviour in the guppy. Animal Behaviour, 62, 591-598.

Takahata, Y., Hiraiwa-Hasegawa, M., TAKasaki, H., \& Nyundo, R. (1986). Newly-acquired feeding habits among the chimpanzees of the Mahale Mountains National Park, Tanzania. Human Evolution, 1, 277-284.

TAKASAKI, H. (1983). Mahale chimpanzees taste mangoes: Toward acquisition of a new food item? Primates, 24, 273-275.

TAKASAKI, H. (1984). A model for relating troop size and home range area in a primate species. Primates, 25, 22-27.

TANAKA, I. (1998). Social diffusion of modified louse egg-handling 
techniques during grooming in free-ranging Japanese macaques. Animal Behaviour, 56, 1229-1236.

TARDE, G. (1969). The laws of imitation (E. C. Parsons, Trans.). Chicago University of Chicago Press. (Original work published 1903)

TERKEL, J. (1996). Cultural transmission of feeding behaviour in the black rat (Rattus rattus). In C. M. Heyes \& B. G. Galef, Jr. (Eds.), Social learning in animals: The roots of culture (pp. 17-48).London: Academic Press

VAN SCHAIK, C. P. (2002). Fragility of traditions: The disturbance hypothesis for the loss of local traditions in orangutans. International Journal of Primatology, 23, 527-538.

van Schaik, C. P., AnCrenaZ, M., Borgen, G., Galdikas, B., KNOTt, C. D., Singleton, I., Suzuki, A., Utami, S. S., \& Merrill, M. (2003) Orangutan cultures and the evolution of material culture. Science, 299, 102-105.

Verbeek, M. E. M., Drent, P. J., \& Wie PKema, P. R. (1994). Consistent individual differences in early exploratory behaviour of male great tits. Animal Behaviour, 48, 1113-1121.

WARNER, R. R. (1990a). Male versus female influences on mating-site determination in a coral-reef fish. Animal Behaviour, 39, 540-548.
WARNER, R. R. (1990b). Resource assessment versus tradition in matingsite determination. American Naturalist, 135, 205-217.

Watanabe, K. (1989). Fish: A new addition to the diet of Japanese macaques on Koshima Island. Folia Primatologica, 52, 124-131.

WEI, W. S. (1990). Time series analysis: Univariate and multivariate methods. Redwood City, CA: Addison-Wesley.

WeINRICH, M. T., SCHILling, M. R., \& BelT, C. R. (1992). Evidence for acquisition of a novel feeding behaviour: Lobtail feeding in humpback whales, Megaptera novaeangilae. Animal Behaviour, 44, 10591072.

Whiten, A. (2000). Primate culture and social learning. Cognitive Science, 24, 477-508.

Whiten, A., Goodall, J., McGrew, W. C., Nishida, T., Reynolds, V., Sugiyama, Y., Tutin, C. E. G., Wrangham, R. W., \& Boesch, C. (1999). Cultures in chimpanzees. Nature, 399, 682-685.

Wilkinson, G. S., \& Boughman, J. W. (1999). Social influences on foraging in bats. In H. O. Box \& K. R. Gibson (Eds.), Mammalian social learning: Comparative and ecological perspectives (pp. 188204). Cambridge: Cambridge University Press. 